\title{
Linear Semicrystalline Polyesters from Fatty Acids by Complete Feedstock Molecule Utilization***
}

\author{
Dorothee Quinzler and Stefan Mecking*
}

\author{
Dedicated to Hans Brintzinger on the occasion of his 75 th birthday
}

Thermoplastic polymers are currently prepared almost exclusively from fossil feedstocks. In view of the limited availability of such feedstocks, alternative renewable resources are desirable in the long term. ${ }^{[1.2]}$ Polymer production from a renewable resource ideally allows for a complete molecular utilization of the feedstock and carries its molecular structure over into the resulting polymers, providing them with specific desirable properties. In this regard, fatty acids from plant oils are attractive substrates as they contain long-chain linear segments. They also possess two functional groups, as required in principle for the generation of thermoplastics by step-growth polymerization. However, the double bond is located in the center of the molecule. For complete utilization of fatty acids in the generation of crystallizable linear polymers, a functionalization at the chain end is required (Scheme 1). Herein we report the preparation and properties of novel semicrystalline polyesters with long-chain hydrocarbon segments based on complete linear incorporation of oleic acid and erucic acid.

carbohydrates by microorganisms or enzymes. Entirely chemical synthetic routes in which the original molecular structure of the utilized plant biomass is substantially retained are an interesting alternative to such biotechnological routes, as they can be efficient in terms of feedstock utilization and reaction space-time yields, and also provide novel properties. Plant oils ${ }^{[-7]}$ are in principle attractive substrates for semicrystalline long-chain polyesters, as the substrate already provides relatively long $\left(\mathrm{CH}_{2}\right)_{n}$ crystallizable segments. This is illustrated by preparation of the difunctional monomer sebacic acid from ricinoleic acid, ${ }^{[8]}$ which is converted into aliphatic polyamides such as nylon- 6,10 with a beneficially low water uptake. Herein, only one side of the fatty acid chain with respect to the double bond is incorporated into the monomer and ultimately the polymer. For longer-chain aliphatic polyesters, a complete incorporation (Scheme 1) is also of particular importance to achieve sufficient melt and crystallization temperatures for thermoplastic processing and applications. Known aliphatic polyesters based on adipic or higher acids suffer from low melting points. $^{\left[{ }^{[-12]}\right.}$

An efficient and highly regio- as well as chemoselective conversion of an internal double bond into a terminal functional group is a challenge for synthetic chemistry. ${ }^{[13]}$ To this end, palladiu$\mathrm{m}$ (II) complexes of very bulky substituted electron-rich diphosphines catalyze the

Polyesters are one of the most important classes of organic polymers, and indeed the more recently developed and commercialized biomass-based polymers are thermoplastic polyesters, namely polylactides and short-chain polyhydroxyalkanoates. ${ }^{[1-4]}$ Their preparation involves conversion of

[*] D. Quinzler, Prof. Dr. S. Mecking

Chair of Chemical Materials Science

Department of Chemistry, University of Konstanz

Universitätsstrasse 10, 78457 Konstanz (Germany)

Fax: $(+49) 7531-88-5152$

E-mail: stefan.mecking@uni-konstanz.de

Homepage: http://www.chemie.uni-konstanz.de/agmeck/

[*⿻一丿火 We thank Lars Bolk for DSC and GPC analysis and Marina Krumova for WAXS.

(a) Supporting information for this article is available on the WWWW under http://dx.doi.org/10.1002/anie.201001510. reaction of ethylene with carbon monoxide and methanol to methylpropionate (methoxycarbonylation) with high rates. ${ }^{[14,15]}$ Remarkably, these catalysts methoxycarbonylate internal octenes to the linear carboxylic acid esters. ${ }^{[16]}$ They have been noted to be compatible with fatty acids; however, from the gas chromatographic data of the reaction mixture presented it appears that the carbonylation products were not formed or isolated with a purity sufficient for utilization as a difunctional monomer for polycondensation. ${ }^{[17-20]}$ This point is critical as highly pure monomers are a prerequisite for achieving any substantial molecular weights in subsequent polycondensation reactions, owing to the correlation $\mathrm{DP}_{n}=$ $1 /(1-p)$ between the degree of polymerization $\left(\mathrm{DP}_{n}\right)$ and the functional group conversion $(p) .^{[21]}$

Exposure of methyl oleate to carbon monoxide and methanol in the presence of catalytic amounts of $\mathrm{Pd}(\mathrm{OAc})_{2} /$ 1,2-bis[(di-tert-butylphosphino)methyl]benzene (dtbpx)/ 
methanesulfonic acid (Pd/oleic acid 1:60) under optimized conditions with respect to concentration of the reactants and temperature $\left(90^{\circ} \mathrm{C} ; 20\right.$ bar $\mathrm{CO}$; methanol) resulted in virtually complete and selective conversion of the unsaturated fatty acid ester (for details, see the Supporting Information). The desired product, dimethyl-1,19-nonadecanedioate, crystallizes from this reaction mixture in more than $99 \%$ purity, as revealed by gas chromatography and NMR spectroscopy of the isolated material (see the Supporting Information). A corresponding long-chain diol component was obtained by reduction of the ester, affording more than $99 \%$-pure nonadecane-1,19-diol. Polycondensation of stoichiometric amounts of dimethyl-1,19-nonadecandioate and nonadecane-1,19-diol catalyzed by titanium alkoxides afforded the novel polyester 1 (Scheme $1, x=1$ ). GPC reveals molecular weights $M_{\mathrm{w}}$ of typically $2 \times 10^{4} \mathrm{~g} \mathrm{~mol}^{-1}\left(M_{\mathrm{w}} / M_{\mathrm{n}}=2\right)$; this data agrees with $M_{\mathrm{n}}$ determined from ${ }^{\mathrm{l}} \mathrm{H}$ NMR spectroscopic analysis of the end groups. This value approaches typical molecular weights of commercial polyesters. ${ }^{[22]}$ The material melts with a peak temperature of $T_{\mathrm{m}}=103^{\circ} \mathrm{C}$ and crystallizes at $T_{\mathrm{c}}=87^{\circ} \mathrm{C}$, with an enthalpy of $\Delta H_{\mathrm{m}}=140 \mathrm{Jg}^{-1}$. These properties compare for example with the ubiquitous thermoplastic low-density polyethylene (LDPE).

Erucic acid is of particular interest for the concept presented herein, as it has an unusually long carbon chain. It is readily available from appropriate rape seed oils, or crambe. Methyl erucate is insufficiently soluble in methanol under the aforementioned conditions, and forms a heterogeneous mixture. This issue can be resolved by employing higher alcohols. Carbonylation of ethyl erucate proceeded smoothly in ethanol to afford diethyl-1,23-tricosanedioate in more than $99 \%$ isolated purity. The ethyl ester was employed as a starting material to circumvent formation of a mixture of three different methyl and ethyl esters, as transesterification may occur under the conditions of carbonylation, which would complicate adjusting the exact stoichiometry in the polycondensation. Reduction afforded more than $99 \%$-pure tricosane-1,23-diol. Polycondensation of stoichiometric amounts of the linear terminal $\mathrm{C}_{23}$ diacid ester and diol, respectively, yielded polyester 2 (Scheme $1, x=5$ ), with $M_{\mathrm{w}}=$ $2 \times 10^{4} \mathrm{~g} \mathrm{~mol}^{-1}\left(M_{\mathrm{w}} / M_{\mathrm{n}}=2\right)$ according to GPC (Figure 1$)$, and $T_{\mathrm{m}}=99^{\circ} \mathrm{C} ; T_{\mathrm{c}}=84^{\circ} \mathrm{C}$ and a high ${ }^{[10.23]}$ melt enthalpy $\Delta H_{\mathrm{m}}=$ $180 \mathrm{Jg}^{-1}$. Wide-angle X-ray scattering (WAXS; Supporting Information) yields a high degree of crystallinity $\chi$ of about $75 \%$ (ca. $70 \%$ for 1 ). These properties also approach those of linear polyethylene in terms of enthalpy per mass associated with melting, reflecting the predominantly hydrocarbon nature of the polymers. ${ }^{[23]}$

The approach presented allows an efficient and complete incorporation of fatty acids into semicrystalline polycondensates, and is demonstrated herein for polyesters. This complete molecular incorporation in a linear fashion is also beneficial for achieving substantial melting points of the aliphatic polyesters. The generic reaction types employed, namely carbonylation, ${ }^{[15]}$ reduction, ${ }^{[24]}$ and polycondensation, ${ }^{[22]}$ are proven on a large industrial scale. The concept is demonstrated herein for two low-cost fatty acids available from a variety of sources. Beyond the novel linear largely hydrocarbon polyesters studied, the long-chain $\alpha, \omega$-diacid
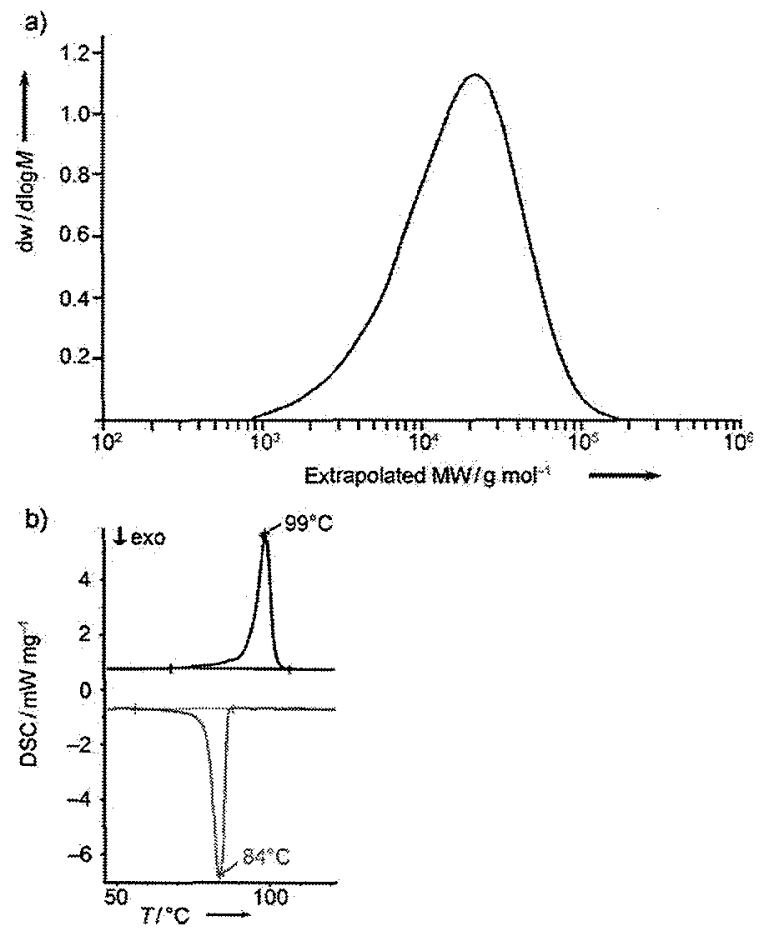

Figure 1. Characterization of poly(1,23-tricosadiyl-1,23-tricosanedioate). a) CPC trace and b) DSC trace. Top: first heating obscured by second heating (black); bottom: first cooling (gray).

esters and diols are obviously of further interest for combination with established condensation monomers (some of which can also be generated entirely from renewable resources) to novel materials.

\section{Experimental Section}

Preparative procedures are exemplified by erucic acid ethyl ester (for full analytical data and procedures, see the Supporting Information). Diethyl-1,23-tricosanedioate: $\mathrm{Pd}(\mathrm{OAc})_{2}(0.079 \mathrm{mmol}), 1,2$-bis [(ditert-butylphosphino)methyl]benzene $(0.395 \mathrm{mmol})$, erucic acid ethyl ester $(4.93 \mathrm{mmol})$, methanesulfonic acid $(0.79 \mathrm{mmol})$, and ethanol $(10 \mathrm{~mL})$ were added into a dry Schlenk tube equipped with a magnetic stirring bar using standard Schlenk and drybox techniques. Vigorous stirring afforded a homogeneous reaction mixture that was transferred by cannula into a $20 \mathrm{~mL}$ stainless-steel magnetically stirred pressure reactor equipped with a glass inlay placed in a heating block. The reactor was closed, pressurized with carbon monoxide (20 bar) and then heated to $90^{\circ} \mathrm{C}$. After $22 \mathrm{~h}$, the reactor was cooled to room temperature and vented. After retrieving the reaction mixture from the reactor, ethanol was removed in vacuo. The crude product was dissolved in dichloromethane and filtrated over a Büchner funnel. Dichloromethane was removed in vacuo. The diethyl-1,23-tricosanedioate thus obtained was recrystallized from ethanol to yield the product in more than $99 \%$ purity in $79 \%$ yield. Tricosane-1,23-diol: Diethyl-1,23-tricosanedioate $(5.22 \mathrm{mmol})$ was dissolved in tetrahydrofuran $(20 \mathrm{~mL})$. This solution was slowly added to a stirred and cooled suspension of $\mathrm{LiAlH}_{4}(13.2 \mathrm{mmol})$ in tetrahydrofuran $(40 \mathrm{~mL})$. After further addition of tetrahydrofuran $(10 \mathrm{~mL})$, the stirred mixture was heated to reflux for 1 hour and then stirred overnight at room temperature. The reaction was quenched by slowly adding water $(0.5 \mathrm{~mL}), 15 \%$ aqueous $\mathrm{NaOH}(0.5 \mathrm{~mL})$, and 
then more water $(1.5 \mathrm{~mL})$. The reaction mixture was filtrated at $40^{\circ} \mathrm{C}$ and the solvent was removed from the filtrate in vacuo. The resulting tricosane-1,23-diol was recrystallized from toluene to yield $1.62 \mathrm{~g}$ $(87 \%)$ of the pure product. Poly(1,23-tricosadiyl-1,23-tricosanedioate): In a $10 \mathrm{~mL}$ Schlenk tube, diethyl-1,23-tricosanedioate $(1.13 \mathrm{mmol})$, tricosane-1,23-diol $(1.13 \mathrm{mmol})$, and $\mathrm{Ti}(\mathrm{OBu})_{4}$ $(0.13 \mathrm{mmol})$ were heated from $110^{\circ} \mathrm{C}$ to $150^{\circ} \mathrm{C}$ at $0.01 \mathrm{mbar}$ over the course of $17 \mathrm{~h}$. After cooling, a white solid was obtained in quantitative yield

Received: March 12, 2010

Published online: May 7, 2010

rwords: crystallinity - homogeneous catalysis . polycondensation - polyesters - renewable resources

[1] D. R. Dodds, R. A. Gross, Science 2007, 318, 1250-1251.

[2] S. Mecking, Angew. Chem. 2004, 116, 1096-1104; Angew. Chem. Int. Ed. 2004, 43, 1078-1085.

[3] A. Steinbüchel, Y. Doi, Biopolymers, Vol. 3a,b,4, Wiley-VCH, Weinheim, 2002.

[4] A. H. Tullo, Chem. Eng. News 2008, 86, 21-25.

[5] U. Biermann, W. Friedt, S. Lang, W. Lühs, G. Machmüller, J. O. Metzger, M. Rüsch gen. Klaas, H. J. Schäfer, M. P. Schneider, Angew. Chem. 2000, 112, 2292-2310; Angew. Chem. Int. Ed. 2000, 39, 2206-2224.

[6] J. O. Metzger, Eur. J. Lipid Sci. Technol. 2009, 111, 865-876.

[7] M. A. R. Meier, J. O. Metzger, U. S. Schubert, Chem. Soc. Rev. 2007, 36, 1788-1802.

[8] F. C. Naughton, J. Am. Oil Chem. Soc. 1974, 51, 65-71.

[9] V. V. Korshak, S. V. Vinogradova, Polyesters, Pergamon Press, Oxford, 1965

[10] L. Mandelkern, R. G. Alamo in Physical Properties of Polymer Handbook (Ed.: J.E. Mark), Springer, New York, 2007, pp. 165-186.

[11] D. Quinzler, S. Mecking, Chem. Commun. 2009, 5400-5402.

[12] This is underlined by the resulting necessity of incorporation of fossil-feedstock based aromatic diacid comonomers: M. Yama- moto, U. Witt, G. Skupin, D. Beimborn, R.-J. Müller in Biopolymers, Vol. 4 (Eds. A. Steinbüchel, Y. Doi), Wiley-VCH, Weinheim, 2002, pp. 299-311.

[13] For enzymatic $\omega$-oxidation of (saturated) fatty acids cf.; a) $\mathrm{S}$. Zibek, W. Wagner, T. Hirth, S. Rupp, S. Huf, Chem. Ing. Tech. 2009, 81, 1797-1808; b) U. Schoerken, P. Kempers, Eur. J. Lipid Sci. Technol. 2009, 111,627-645.

[14] W. Clegg, G. R. Eastham, M. R. J. Elsegood, R. P. Tooze, X. L. Wang, K. Whiston, Chem. Commun. 1999, 1877-1878.

[15] A. H. Tullo, Chem. Eng. News 2009, 87, 22-23.

[16] R. I. Pugh, E. Drent, P. G. Pringle, Chem. Commun. 2001, 14761477.

[17] C. Jiménez-Rodriguez, G. R. Eastham, D. J. Cole-Hamilton, Inorg. Chem. Commun. 2005, 8, 878-881.

[18] C. Jiménez-Rodriguez, Ph.D. thesis, University of St. Andrews, 2004

[19] Remarkably, the multiple unsaturated linoleate and linolenate are also converted into the saturated, linear $\alpha, \omega$-diester, which is advantageous for the utilization of technical-grade fatty acid esters. $^{[17]}$

[20] See also: Y. Zhu, J. Patel, S. Mujcinovic, W. R. Jackson, A.J. Robinson, Green Chem. 2006, 8, 746-749.

[21] W. H. Carothers, Trans. Faraday Soc. 1936, 32, 39-52

[22] H. Köpnick, M. Schmidt, W. Brügging, J. Rüter, W. Kaminsky in Ullmann's Encyclopedia of Industrial Chemistry, Vol. 28, 6th ed., Wiley-VCH, Weinheim, 2003, pp. 75-102.

[23] From $\Delta H_{\mathrm{m}}$ (determined by DSC) and $\chi$ (determined by WAXS), an enthalpy of fusion $\Delta H_{u}$ of the crystalline portion of about $200 \mathrm{Jg}^{-1}$ (1) and $240 \mathrm{Jg}^{-1}$ (2) is estimated by comparison to $\Delta H_{4}=293 \mathrm{Jg}^{-1}$ for linear polyethylene. Poly(decamethylene sebacate) as an example of a long-chain linear aliphatic polyester from currently accessible monomers melts with $\Delta H_{\mathrm{u}} 148 \mathrm{Jg}^{\text {m1 }}$ $\left(T_{\mathrm{m}}=80^{\circ} \mathrm{C}\right){ }^{[10]}$

[24] In this work, reduction of diacid esters to diols was performed with inorganic hydrides, as this is convenient on a laboratory scale. Industrially, catalytic reduction of esters to alcohols with hydrogen as a reagent is an established reaction. 